\title{
AS RELIGIŌES AFRO-BRASILEIRAS: SUBSÍDIOS PARA O ESTUDO DA ANGÚSTIA ESPIRITUAL
}

\author{
Isabel Cristina Fonseca da Cruz*
}

CRUZ. I. C. F da. As religiōes afro-brasileiras: subsídios para o estudo da angistia espiritual.

Rev.Esc.Enf.USP , v. 28, n.2, p. 125-36, ago. 1994.

Neste estudo, apresentamos alguns aspectos sobre as religiöes afro-brasileiras, no sentido de subsidiar o diagnóstico e tratamento da angústia espiritual (4.1.1. Taxonomia I - NANDA). São abordadas as seguintes religiōes: candomblé, umbanda, quimbanda, islä e vodu, com destaque para as questōes referentes ao processo saúde. doença. Diante da escassez de pesquisas sobre a saúde dos brasileiros de origem africana, ressaltamos a necessidade de se realizar estudos sobre o tema.

UNITERMOS: Anguistia espiritual; Espiritualidade; Religião; Raça Negra.

\section{INTRODUÇÃO}

A espiritualidade é uma dimensão humana que se desdobra em fenômenos ainda pouco familiares à enfermeira. A ambigüidade presente no conceito associada a preconceitos étnicos têm resultado no desconhecimento sobre o diagnóstico e tratamento desses fenômenos na população brasileira, em geral, e na população afro-brasileira, em particular.

Neste estudo, consideramos que o diagnóstico de enfermagem é um julgamento clínico sobre a resposta do indivíduo a um processo vital ou problema de saúde, sendo que esta resposta fornece a base para a seleção das prescriçōes e para o estabelecimento de resultados pelos quais a enfermeira é responsável (NORTH AMERICAN NURSING DIAGNOSIS ASSOCIATION, 1990).

Para nomear esta resposta do indivíduo, ou seja, este diagnóstico de enfermagem, utilizamos a Taxonomia I da NANDA - North American Nursing Diagnosis Association (NÓBREGA; GARCIA, 1992) na qual estão descritos os fenômenos que podem, e devem, ser diagnosticados e tratados pela enfermeira. Entre estes fenômenos, há um, referente à transcendência do ser, classificado dentro do padrão de resposta humana Valorizar.

Enfermeira. Doutora em Enfermagem da Escola de Enfermagem da USP. Professora Titular do Dept" de Enfermagem Médico-Cinirgica da Escola de Enfermagem da Universidade Federal Fluminense. Coordenadora do NESEN - Núcleo de Estudos sobre Saúde e Etnia Negra. 
Segundo CRUZ; CRUZ (1991) Valorizar é um padrão de resposta humana que envolve o julgamento sobre o significado ou a importância das coisas, ou seja, daquilo que existe ou pode existir. Nesta área de estudo pouco tem sido desenvolvido e, até o momento, existe apenas um diagnóstico de enfermagem identificado: a angústia espiritual.

Enquanto um diagnóstico de enfermagem, a angústia espiritual é conceituada como um estado no qual o individuo experimenta uma ruptura no principio de vida, o qual permeia todo o seu ser, integra e transcende sua natureza biológica e psicossocial (NÓBREGA; GARCIA, 1992). A angústia espiritual compreende não só uma preocupação expressa com o sistema de crenças, mas também o questionamento sobre o significado da vida, do sofrimento, dos temas morais, éticos ou das condutas terapêuticas, entre outros.

Os fatores relacionados a este diagnostico, isto é, os fatores que podem causá-lo sãa os seguintes: separaçãa de laços religiosos ou culturais e desafio ao sistema de crenças e valores em razão das implicaçōes morais ou éticas da terapia ou de intenso sofrimento (NOBREGA; GARCLA, 1992).

Estas considerações iniciais sobre o diagnóstico de angústia espiritual nos remete de certa forma à religiosidade dos individuos, por essa razāo, destacamos a contribuição trazida pela pesquisa de HENSE (1989) sobre o cliente cirúrgico e sua espiritualidade. A motivação para o nosso trabalho surgiu quando HENSE, por ter entrevistado catolicos e protestantes, afirmou que o perfil dos seus depoentes era semelhante ao perfil religioso da maioria do povo brasileiro.

Não temos por propósito neste estudo contestar numericamente a afirmação de HENSE (1989). Interessa-nos sobretudo discutir a composição plural desta naçāo e a necessidade de trazer esta pluralidade para dentro das nossas pesquisas de modo que os resultados revelem esta multiplicidade de culturas. Acreditamos que só desta forma podemos neutralizar o discurso ideológico discriminador que ainda permanece em nossa sociedade, objetivado pelos indicadores sociais que confirmam o segregacionismo (FRY, 1988).

Fazemos nossas as palavras de FERREIRA (1988) quando afirma que historicamente perdemos contato com o mundo de onde viemos, a África, e consequentemente perdemos contato com a cultura popular, com a religião e com a ancestralidade. Entendemos que já é tempo de retomar este contato, de conhecer um pouco mais sobre nós mesmos e sobre as nossas origens não-européias.

No que se refere à enfermagem, em especial, há o desafio de realizar pesquisas que sejam congruentes com as realidades vividas por populaçōes etnicamente diversas. Isto exige o re-exame das bases teóricas, da representação da amostra, dos instrumentos de coleta de dados e do referencial de análise. Requer, principalmente, avaliação sobre a relevância dos achados dentro do contexto de forças e limitações. PORTER; VILLARRUEL (1993) também questionam a ausência dos conceitos de cultura (etnia) ou raça (cor) nas pesquisas de enfermagem, uma vez que estes conceitos conotam diferenças para os referenciais teóricos. Consideram ainda que a perspectiva unicul- 
tural diminui a capacidade do pesquisador em elaborar interpretaçōes alternativas. As autoras são taxativas em relação às pesquisadoras da área de diagnóstico de enfermagem, entre as quais nos incluímos: Se as enfermeiras pesquisadoras pretendem nomear as respostas humanas à saúde e à doença, elas têm a obrigação de lidar com as diferenças da forma mais acurada possivel.

Assim, partindo dos possíveis fatores relacionados ao diagnóstico de angústia espiritual, consideramos que a dissolução sistemática dos valores culturais da etnia negra pode ser determinante para este diagnóstico, sendo além disso agravada pela forma atávica com que se considera as religiōes de origem judaico-cristãs hegemônicas na sociedade brasileira.

Diante do que foi anteriormente discutido, o nosso proposito, neste estudo, é, contrapondo a afirmação de HENSE (1989), apresentar a vertente afro-brasileira da religiosidade responsavel, neste quase meio milênio de história, por uma significativa influência na cultura de 63 milhões de brasileiros descendentes de escravos (SANTOS, 1988).

$\mathrm{O}$ viés ideológico, caracterizado pela ausència do item cor/raça nos documentos sobre a população brasileira, tem por base a tese assimilacionista na qual os não-brancos ocupam uma posição subalterna devido à classe, não a raça. Este viés é responsável pela escassez de pesquisas sobre o processo bem-estar/saúde/doença/mal-estar em pessoas da etnia negra (CRUZ, 1994).

A consciència de que o mito da democracia racial é uma forma sutil e perversa de alijar a parcela afro-brasileira desta sociedade, somada ao compromisso político com este segmento de onde viemos, para onde voltamos e do qual nunca saímos, motivou-nos a realizar este estudo. Nele tangenciamos o candomblé, a umbanda, a quimbanda, o islā e o vodum.

Da literatura consultada, procuramos extrair elementos religiosos relacionados ao processo saúde-doença. Sempre que possível, estes elementos foram organizados conforme as categorias identificadas por HENSE (1989) para a espiritualidade, tais como: reconhecimento de um ser superior, busca de significado para a doença, apoio espiritual, confiança e afiliação religiosa.

Porém, antes de iniciar a abordagem sobre as religiōes afro-brasileiras, mesmo podendo incorrer no risco da obviedade, gostariamos de enfatizar que há diferença entre espiritualidade e religiosidade. A religião (do latim religare significa manter junto) fornece ao individuo valores, códigos e rituais que influenciam tanto a vida do fiel quanto daquele que não é adepto. A religião enquanto influência cultural tem recebido pouca atenção da enfermagem. segundo MANSEN (1993).

A ênfase que se dá apenas às práticas religiosas faz com que pensemos que as necessidades espirituais da clientela podem ser preenchidas com ritos, rituais e presença de sacerdotes. Aprendemos a reconhecer como indicadores espirituais a leitura de bíblias e a visita de clérigos apenas das religiōes judaico-cristãs, negligenciando outras manifestações religiosas e sinais relacionados a processos espirituais internos, caracterizados pela meditação e preocupação com a transcendência, por exemplo. Assim, ainda que neste estudo abordemos a angústia espiritual pela sua vertente religiosa, entendemos que este diagnóstico se insere numa categoria muito mais ampla. 


\section{FUNDAMENTOS DAS RELIGIŌES AFRO-BRASILEIRAS}

Um aspecto crucial neste estudo sobre a religiosidade afro-brasileira reside no fato de compreender os cultos de origem africanas enquanto verdadeiras religiōes e não como seitas. Cabe ressaltar que as religiões afro-brasileiras possuem um corpo sacerdotal, filosofia, ritos, enfim, uma estrutura que as caracterizam como instituições. Considerá-las seitas é , na realidade, uma tentativa de reduzir a sua importancia e de classificar as pessoas que as praticam como um punhado de fanáticos.

A rigor, as religiōes afro-brasileiras são patrimônio desta naçāo e compõem, particularmente, o universo cultural da raça negra brasileira que foi sequestrada da África para a Europa e Américas e mantida nestes continentes na condição de escrava, sob tortura física e psicológica, por mais de quatrocentos anos (CONCEIÇÃO, 1993). Temos que reconhecer que um século. de aboliçāo do escravismo não é suficiente para alterar uma sólida estrutura ideológica construída para justificar a exploração e a negação das pessoas negras enquanto seres humanos auto-determinados e transcendentes.

Portanto, não esperemos passivamente que outros quatro séculos transcorram para que finalmente as estruturas e instituições sociais se alterem em benefício dos descendentes dos escravos e escravas africanos.

Mesmo após o fim oficial do escravismo, as religiōes afro-brasileiras foram relegadas à clandestinidade, sendo objeto de repressões policiais sistemáticas ao longo da primeira metade deste século (REIS, 1988; BRAGA, 1993). As religiōes afro-brasileiras constituíram focos de resistência e luta contra o estatuto da escravidão, contra a repressão eclesiástica e policial.

Conseguiram, mesmo sob repressāo, manter suas práticas e influenciar o catolicismo com tradições mágicas e pagãs, por meio das irmandades leigas de homens de cor (São Benedito, Santa Efigênia, N. Sra. Do Rosário, entre outras). Participamos nos espaços exteriores às irmandades das inúmeras encenaçōes que nos remetem à cosmogonia e à saga africana na forma de Reizado, Congada, Moçambique, Maracatu, Folia de Reis, Carnaval e lavagem das escadarias da igreja do Bonfim, entre outras tantas (LUZ, 1993). Na atualidade, a luta das religiōes afro-brasileiras está voltada contra o preconceito e a desinformação, além da manutenção das tradições e abandono do sincretismo.

É frente a este referencial que apresentamos a seguir alguns aspectos sobre estas religiōes, obtidos principalmente nos textos de História e Ciências Sociais, visando contribuir para a discussão sobre o tema dentrı da área da Saúde.

\section{o Candomblé}

A palavra candomblé origina-se de candombe (negro, em banto) e ilê (casa, mundo, em iorubá) e significa, casa de negro. $O$ candomblé chegou ao 
Brasil com os negros iorubás e jejes (fon ou mina) escravizados, que na África habitavam a região onde hoje é a Nigéria e o Benin, e com os negros bantos, da parte sul do continente (LODY, 1987).

Em razão dos diversos grupos étnicos negros, encontramos dentro do candomblé várias nações ou variantes, a saber: Angola (banto), Ketô-Nagô (iorubá), Jeje (fon), Jexá ou Ijexá (iorubá), Caboclo (afro-brasileiro), e Congo (banto) (RAMOS, 1979; LODY, 1987; LOPES et al, 1987).

No candomblé, cultua-se como ser superior Olorum (senhor do céu) ou Olodumaré (onipotente e eterno), divindade suprema que não tem representação material. Olorum criou o mundo em quatro dias, fez uma aliança com os seres humanos, representada pelo arco-íris, e se recolheu para descansar, entregando a solução dos problemas do mundo aos orixás (PORTUGAL, 1986).

Os orixás, divindades intermediárias, juntos com Olorum, proporcionam apoio espiritual ao fiel, ao povo de santo. Os orixás governam o mundo, a humanidade. e o ser humano. Mas também são parte deste mundo, enquanto elementos da natureza; parte da humanidade, enquanto antepassados míticos; e parte do ser humano, enquanto componentes de sua personalidade.

Dentre os orixás cultuados no Brasil, destacamos o Omolú e Ossãe por apresentarem uma estreita relação com os conceitos de doença e cura. Omolú, saudado pela expressão Iatotô!, é o orixá das doenças da pele, responsável também pelas epidemias, mortes e desgraças que afetam a comunidade. Ossãe, que tem por saudação grito Eueê ô!, é um orixá cujo domínio refere-se ao conhecimento das folhas e ervas próprias para os banhos e bebidas ritualísticas, para os sacrifícios e para a cura das doenças.

No candomblé, as divindades têm caracteristicas humanas, dadas por virtudes e defeitos; e os fiéis possuem, por sua vez, características divinas, pois além de serem filhos dos orixás, carregam o ori, termo que designa a cabeça, sendo, além disso, uma divindade guardiã do destino (VOGEL et al, 1993).

No candomblé, não há a idéia de pecado, de inferno ou de purgatório o que, contudo, não implica em um existir permissivo. O referencial de vida é a própria vida uma vez que a existência transcorre em dois planos paralelos: no aiê (mundo) e no orum (além). Assim, cada elemento material tem seu duplo espiritual e abstrato no orum e cada elemento existente no orum tem sua representação material no aie (SANTOS, 1993). Segundo VOGEL et al (1993), a vida e a morte são variaçōes de sentido inverso e ambas dependem do ser humano que faz a sua vida como também pode fazer a sua morte.

No que se refere à afiliaçāo, existe no candomblé. Além do culto aos orixás, cerimônias dirigidas para os espíritos dos antepassados femininos (Geledé) e masculinos (Egun), presentes nas naçōes Kêto e Jeje. Segundo LUZ (1983), os ancestres femininos, pela imensa força que possuem, não se caracterizam pela aparição, consubstanciando-se em máscaras e animais; já os eguns possuem culto especial, exclusivamente masculino.

A religião nagô ou iorubá ou candomblé, historicamente próxima às camadas mais resistentes e conscientes de sua origem africana, é celebrada em terreiros ou roças. O seu altar é denominado peji e nele está 'plantado' o 
precioso axé, força que assegura a existência dinâmica (SANTOS, 1993; VOGEL et al, 1993).

No peji estão guardados ainda os assentamentos dos fiéis. Estes assentamentos são objetos ou elementos da natureza cuja substância e configuraçāo abrigam a força dinâmica do orixá que representa o apoio espiritual do fiel. Por ser uma representação viva do orixá, o assentamento requer alimentos e cuidados especiais implementados durante liturgias privativas, denominadas ossé. Estas cerimônias são conduzidas pelo sacerdote ou babalorixá (pai de santo) ou pela sacerdotisa, a iolorixá (mãe de santo).

Cabe destacar o reconhecimento e o poder que a mulher exerce dentro do candomblé, poder este que geralmente lhe é negado na sociedade. O poder feminino das lás ou labás nas comunidades nagô é profundamente venerado por assegurar não só a continuidade física, mas também de plantar e semear os modos e valores do terreiro (SANTOS; SANTOS, 1993).

Por ser uma religião essencialmente iniciática, a liturgia do candomblé só é conhecida pelos fiéis que se submetem ao processo de iniciação. Os ritos iniciáticos, cujos conhecimentos são transmitidos de forma oral, acontecem ao longo de toda a vida religiosa e possuem duração variável (SANTOS; SANTOS, 1993). Desta forma lenta e gradual desvelam-se os mistérios e segredos do candomblé e a primeira estação desta jornada é o borí. A palavra bori designa o ato de dar comida à cabeça, concebida como algo à parte, especial e sagrado (VOGEL et al, 1993).

A morte só se intimida com o sacrificio e este depende de se saber o que desejam os orixás, por intermédio do jogo dos búzios. Em algumas cerimônias acontece o sacrifício ritualístico de animais para oferecimento aos orixás e consequente acumulação de axé. A prática do sacrificio de animais costuma ser contestada pelos não adeptos. Cabe observar porém que. historicamente, o que os africanos possuiam de mais precioso para ofertar ao orixá era a sua comida da qual ele obtinha a sua força vital ou axé. Assim, nestas cerimônias algumas partes do animal sacrificado são ofertadas ao orixá e o restante do animal, transformado em comidas saborosas, é comungado entre os participantes da festa.

A riqueza da liturgia do candomblé e de sua cosmogonia, juntamente com suas implicaçōes para o processo saúde-doença, extrapolam o âmbito deste estudo. Entretanto, apontamos para a necessidade de se conhecer este universo para que possamos identificar quais características definidoras os clientes adeptos desta religião apresentam quando manifestam anguistia espiritual e quais fatores relacionados desencadeiam este diagnóstico.

\section{A Umbanda}

A umbanda originou-se entre a populaçāo de etnia banto (regiāo de Angola. Moçambique e parte sul da África) que trouxe para o Brasil uma religião voltada para o culto dos ancestrais africanos e familiares que durante a sua passagem pela vida se distinguiram pela sabedoria (MAGNANI, 1986; LUZ, 1993). 
Os bantos (que na língua quibundo significa humanidade) foram fixados, no Brasil, principalmente em Minas Gerais, Rio de Janeiro e São Paulo, nas atividades agrícolas e auriferas.

Na umbanda acredita-se na idéia de um ser superior, Zambi, que exprime a infinitude da existência. Além disso há a crença na existência interativa entre o mundo visivel e o mundo invisível, na possibilidade de estabelecer por meio do rito, relações com o mundo dos invisíveis, propiciando a sua atuação no mundo dos vivos.

Cabe ressaitar que a umbanda (e o candomblé numa escala menor) fez do sincretismo a sua ponta de lança contra a discriminação religiosa, isto é, só restou ao negro, segundo LUZ (1993) africanizar o cristianismo. Adotou as imagens católicas para poder continuar cultuando as divindades banto-iorubá, porém dentro de uma dinâmica ritual que em nada se aproxima do culto católico (LUZ, 1983). Observamos, porém, que a associação entre os orixás e santos católicos não aconteceu de forma aleatória, mas a partir das referências dadas pela cosmogonia iorubá e banto.

Quanto à afiliação religiosa, os cultos umbandísticos são denominados giras, enquanto que o sacerdote ou sacerdotisa, pai ou mäe de santo. Os iniciados são conhecidos como médiuns e incorporam os espíritos dos ancestrais (eguns); ao contrário do candomblé no qual o rito de possessão significa a manifestação da divindade ou orixá no corpo de seu filho. No candomblé, os espiritos dos mortos ou eguns não possuem o corpo do fiel, eles manifestam-se na sua roupa (MAGNANI, 1986; LOPES et al, 1987).

Quanto à busca de um significado para a doença, podemos depreender que o equilibrio da existência se caracteriza pela atuaçào de fluxo de força mística, cabendo aos rituais umbandistas manter afastados dos fiéis as forças invisiveis que regem doenças, perturbaçōes, infelicidade e fome, entre outros fenômenos (LUZ, 1983; 1993).

Segundo MOURA (1988), a umbanda é a religião mais difundida no Brasil, tendo em vista a prática de medicina popular que acontece em seus terreiros. Esta observação de MOURA nos remete para as formas como a população supre as carências advindas ou da precariedade do Sistema de Saúde ou do reducionismo dos paradigmas utilizados pelos profissionais da área.

\section{A Quimbanda}

Para melhor compreensão sobre o surgimento da quimbanda entre as religiōes afro-brasileiras é necessário, primeiramente, conhecer um pouco da trajetória do culto de Exú, desde a África até o Brasil.

$\mathrm{Na}$ África, Exú está associado ao poder da fecundação e é representado por uma imagem fálica (devido ao formato da sua cabeça ser igual ao de um pênis, Exú não carrega nada sobre ela e isto lhe confere uma característica de independência). Somado a este poder, existe ainda o de ser intermediador entre os seres humanos e os orixás. 
Exú é um principio que representa e transporta o axé, participando forçosamente de tudo, assim, cada ser existente no universo (orum e aîे) tem o seu Exú, assim como no catolicismo cada um tem o seu anjo de guarda e para ele acende velas e pede proteção. Sem Exú, portanto, nada se movimenta, nada se desencadeia, nenhuma ação é concretizada (SANTOS, 1993; LUZ, 1993).

Cabe a Exú garantir o ciclo da existência, promovendo a relação sexual. Está associado à placenta responsável pelo desenvolvimento fetal. Exú é responsável pela circulação do interior do corpo, pela respiração, pela sucção, pela ingestão de alimentos e pela comunicação. Abre e fecha os caminhos e acompanha o orixá Ikú (morte).

No Brasil, o culto a Exú concentrou-se mais no seu poder de mensageiro e intermediador, tendo em vista que ao escravo africano não interessava a procriação, mas sim a proteção de seus orixás na sua luta pela liberdade. Assim, o poder de Exú cresceu de tal forma a ponto deste principio da existência ser cultuado como uma divindade, como um orixá.

Nos cultos iorubás ele é sempre o primeiro a ser saudado e recebe parte das oferendas de qualquer ritual, permitindo assim o sucesso da liturgia. $\mathrm{Na}$ umbanda, as giras de Exú, de um modo geral, acontecem depois da meia-noite.

No Brasil, apenas no culto iorubá a imagem representativa de Exú permanece com sua característica fálica. Diante da repressão eclesiástica e, tendo em vista que o espaço físico de Exú são as estradas, as encruzilhadas e os portões, os negros escravizados adotaram do catolicismo a representação do diabo para, com esta imagem, temida pelos brancos, afugentar dos terreiros os senhores e neles imprimir o medo da quimbanda (feitiçaria, em banto).

A quimbanda surge como uma manifestação contrária ao embranquecimento da umbanda, caracterizado pela manutenção do sincretismo religioso e pelo discurso judaico-cristão kardecista. Mas, em decorrência da imagem sincrética e ideológica de Exú, principal divindade da quimbanda, esta religião é percebida como culto do mal, sofrendo portanto a maior carga de repressão (LUZ, 1983; MOURA, 1988).

Atribui-se aos sacerdotes e sacerdotisas desta religião a capacidade de fechar o destino das pessoas e abrí-los para atuação dos espíritos malignos. Porém, cabe ressaltar que na cosmogonia afro-brasileira os conceitos de bem e mal; certo e errado são contextuais e dinâmicos, não representando categorias prescritivas ou maniqueístas (LUZ, 1993).

É na quimbanda que as camadas mais proletarizadas encontram as condições para fechar o corpo e, assim, protegerem-se das agressões de uma sociedade excludente e violenta.

\section{O Islä}

O tráfico para o Brasil em sua última fase coincide com o processo de islamização da África, em regiões do Senegal e no norte da Nigéria. A religião de Maomé e a cultura malê chegaram no Brasil com os negros escravizados. 
Os malês ou muçulmis eram adeptos de um islamismo híbrido no qual o ser superior e único era Olorum-uluá (Olorum, iorubá e Alá, árabe).

Foi esse islamismo que criou a mítica de uma etnia altiva, insolente, insubmissa e revoltosa, conhecida como os negros minas. Assim chamados todos aqueles cativos vindos da região do antigo Sudão e embarcados no forte de São Jorge da Mina (LOPES et al, 1987).

Quanto ao apoio espiritual, embora monoteístas, os malês não se separavam de seus talismãs e mandingas (breves e escapulários) que eram fragmentos de papel com inscriçōes em árabe do Alcorão, a bíblia islâmica. Não é sem razão que o termo mandinga faz parte do nosso vocabulário significando feitiço, porque os malês eram temidos pelas suas feitiçarias e pelo poder de seus patuás.

No que se refere à categoria afiliação religiosa, temos que o sacerdote, - Imā, era conhecido como lemano e seu auxiliar, como ladano, havendo ainda um corpo de conselheiros constituídos pelos idosos. A oração, ou salah, era praticada cinco vezes ao dia. Por motivos óbvios apenas a peregrinação à Meca não acontecia, no mais todas as práticas muçulmanas eram observadas pelos malês, tais como: não comer carne de porco, usar túnicas brancas e gorros (filá) vermelhos, praticar a poligamia, entre outras.

Do islamismo malê, enquanto prática religiosa, nāo existe mais nada no Brasil visto que estes escravos ou foram mortos em sucessivas rebeliōes na Bahia ou foram deportados por esta mesma razão (RAMOS, 1979).

$\mathrm{O}$ islamismo negro ressurgiu com os imigrantes de origem árabe estando praticamente restrito a esta comunidade. Mas, ainda que nos faltem dados discretos, cabe ressaltar o surgimento de uma nova forma de islamismo de origem afro-caribenha denominado rastafarianismo (nome derivado de Ras Tafari, primeiro nome de Haillé Salassié, imperador da Etiópia).

Os rastas cultuam Jah e têm uma cultura baseada em alimentaçāo vegetariana e numa forma própria de cuidar da lä (cabelo) que não pode ser penteada, apenas trançada em dreadlocks. Enquanto naturistas não bebem bebidas alcoólicas, não usam drogas, nem fumam tabaco. Por considerarem a Canabis sativa uma erva sagrada, permitem o seu fumo. Muitas de suas práticas os tornam semelhantes aos muçulmanos, principalmente no que se refere ao papel subalterno que reservam às mulheres.

\section{O Vodum}

Das religiões afro-brasileiras, o vodum é provavelmente a menos conhecida e também a de menor difusão.

$\mathrm{O}$ vodum (vodum, significa orixá) chegou ao Brasil dentro de navios tumbeiros que transportavam como carga os negros escravizados provenientes do Daomé, etnia jeje. Nesta religião cultua-se como ser superior Dan ou Dangbé, a serpente sagrada.

$O$ vodum é uma religião que só possui sacerdotisas, estando o homem totalmente excluído destas funções. Esta prática religiosa, pouco conhecida 
ainda, é encontrada na cidade do Recife e em Salvador, de forma adulterada, segundo RAMOS (1979). A sua melhor representação é praticada em São Luís do Maranhão em um dos mais antigos templos religiosos brasileiros, a Casa das Minas.

\section{CONSIDERAÇŌES FINAIS}

Em síntese, a espiritualidade tem vertentes relacionadas à religiosidade e à transcendência. A espiritualidade é uma dimensão humana na qual existem fenômenos, como a angústia espiritual, que cabe à enfermeira diagnosticar e tratar de forma autônoma.

Entretanto, para que possamos compreender o processo de bem-estar/saúde/doença/mal-estar do povo brasileiro e, dentro deste processo os aspectos referentes à espiritualidade e à angístia espiritual, temos que estudá-lo na sua totalidade, sem excluir nenhum segmento.

Neste sentido, o papel da religiosidade afro-brasileira nas questões de saúde e doença precisa ser mais estudado pelos profissionais da área. Pela leitura dos trabalhos históricos, tomamos conhecimento, por exemplo, que em 1685, a parda Clara Garces foi denunciada por viver curando a todos que a sua casa vinham doentes, usando de calundus e bonifrates. Em uma época em que a assistência para os problemas de saúde dependia em grande parte do uso de ervas, a vida e a morte de muitos dependia de curandeiras e curandeiros (REIS, 1988).

Isto nāo é um passado morto. Concordamos com REIS (1988) quando afirma que estas formas de compreender o mundo e resolver os problemas da existência continuam fazendo parte do nosso cotidiano. O pensamento mágico, elemento das religiões afro-brasileiras e do catolicismo popular, representa um aspecto importante das relações sociais e de poder, e pela lógica desse pensamento, as pessoas não caem doentes ou sofrem infortúnios só por obra da natureza, do indivíduo comum ou do destino. As pessoas são enfeitiçadas e há os especialistas que enfeitiçam e os que curam. Acrescentariamos que neste processo encontramos, provavelmente, um mesmo especialista que enfeitiça, cura e cuida.

Ainda que neste estudo tenhamos apenas tangenciado o complexo universo das religiōes afro-brasileiras, em especial no que se refere ao adoecer, curar e cuidar, vemos que além de Deus ou Jeová há Olodumaré e Zambi, que o apoio espiritual pode não estar apenas na Bíblia mas em assentamentos, colares e talismãs. A assistência espiritual pode ser dada para uns pelo pastor ou padre, mas para outros, pela Ialorixá.

No tocante ao significado de angústia espiritual para os adeptos das religiōes afro-brasileiras em particular, somente uma investigação desenvolvida junto a esta população poderá trazer fatos elucidativos. Para tanto é necessário primeiramente vencer a barreira do preconceito e da desinformação sobre as culturas negras e corrigir as distorções ideológicas existentes. 
CRUZ, I. C. F. da Afro-Brazilian religions: issues related to the nursing diagnosis spiritual

distress. Rev. Esc. Enf. USP, v.28, n.2, p. 125-36, aug. 1994.

This paper discuss the Afro-Brazilian religions (candomble, umbanda, quimbanda, muslim, and vodum, and poits out the issues related to the spiritual distress as a nursing diagnosis.

UNITERMS: Spiritual distrees; Spirituality; Religion; Afro-Americans.

\section{REFERÈNCIAS BIBLIOGRÁFICAS}

BRAGA, J. Candomblé da Bahia: repressão e resistência. Rev.USP . n.18, p. 52-9. 1993.

CONCEIÇÀO, F.. Isto foi um sequestro./Apresentado no Seminario Nacional de Universitários Negros - SENUN - UFBA. Salvador, 1993/

CRUZ, I.C.F. da Mulher negra: tópicos sobre saúde e doença. Rio de Janeiro, NESEN - Núcleo de Estudos sobre Saúde e Etnia Negra, 1994.

CRUZ, I.C.F. da; CRUZ, D. de A.L.M. da Os padrōes de comportamento humanos: uma proposta de traduçào dos termos da Taxonomia I sobre diagnosticos de entermagem. Rev.Esc.Enf.USP , v.25, n.1, p.16-9, 1991.

FerReIRA, G.A Identidade negra; descaminhos. Sāo Paulo Perspec, v. 2, n.2, p. 35-7, 1988.

FRY, P. Somos todos racistas. Ci.Hoje, v.8, n.46, p.68-72, 1988.

HENSE, D.S.S. A espiritualidade no contexto da experiência do paciente cirurgico. Rev.Esc.Enf.USP , v.23, n.3, p.329-36, 1989.

LODY, R. Candomblé : religiào e resistência cultural. São Paulo, Ática, 1987.

LOPES, H.T. et al. Negro e cultura no Brasil: pequena enciclopédia da cultura brasileira. Rio de Janeiro, UNIBRADE/UNESCO, 1987.

LUZ. M.A. Cultura negra e ideologia do recalque. Rio de Janeiro, Achiame, 1983.

Do tronco ao opá exin: memoria e dinàmica da tradição africana-brasiieira. Salvador, SECNEB, 1993.

MAGNANI,J.G.C. Umbanda . São Pauio, Ática, 1986.

MANSEN, T.J. The Spiritual dimension of individuals: conceptuai development. Nurs.Diagn ., v.4, n.4, p.140-7, 1993.

MOURA, C. Sociologia do negro brasileiro. São Paulo, Ática, 1988. 
NÓBREGA, M.M.L. da; GARCIA,T.R. Uniformizacāo da linguagem dos diagnósticos de enfermagem da NANDA: sistematizaçāo das propostas do II SNDE. Joāo Pessoa, CNRDE/GIDE-PB, 1992.

NORTH AMERICAN NURSING DIAGNOSIS ASSOCIATION. Taxonomy I - revised with the official diagnostic categories. St.Louis, 1989.

PORTER, C.P.; VILLARRUEL, A.M. Nursing research with African American and Hispanic people: guidelines for action. Nurs.Outlook , v.41, n.2. p.59-67, 1993.

PORTUGAL, F. Ossayn : o orixá das folhas. 3.ed. ECO,1986.

RAMOS, A. As culturas negras no novo mundo. 4.ed. Sảo Paulo, Nacional, 1979.

REIS, J.J. Magia jeje na Bahia: a invasão do calundu do Pasto de Cachoeira, 1785. Rev.Bras.Hist. , v.8, n.16, p.57-81, 1988.]

SANTOS, D.M. dos; SANTOS, J.E. dos A cultura nagô no Brasil: memória e continuidade. Rev.USP, n.18, p.40-51, 1993.

SANTOS, H. Escravidão e barbárie. Sāo Paulo Perspec., v.2, n.2, p.18-9, 1988.1

SANTOS, J.E. dos Os nagô e a morte. 6.ed. Petrópolis, Vozes, 1993.

VOGEL, A. et al. A galinha-d'angola: iniciaçåo e identidade na cultura Afro-Brasileira. Rio de Janeiro, Pallas/FLACSO, Niteroi, EDUFF, 1993. 